\title{
Case series of cerebral infarction with Trousseau's syndrome associated with malignant gynecological tumors
}

\author{
MASAKO ISHIKAWA, KENTARO NAKAYAMA, TOMOKA ISHIBASHI, \\ EMI SATO, KOHEI NAKAMURA, HIROSHI KATAGIRI and SATORU KYO
}

Department of Obstetrics and Gynecology, Shimane University School of Medicine, Izumo, Shimane 6938501, Japan

Received December 18, 2015; Accepted April 15, 2016

DOI: $10.3892 / \mathrm{mco} .2016 .888$

\begin{abstract}
The association between neoplastic disease and thromboembolic disorders was first recognized by Trousseau in 1865. Blood coagulation abnormalities have been reported in the majority of patients with cancer, including those with ovarian carcinoma. However, Trousseau's syndrome (TS) has rarely been reported in women with ovarian carcinoma. We herein report a case series of TS, notably in the brain, in association with gynecological malignant disease, and emphasize the difficulties associated with the management of these thromboembolic effects. The aim of this study was to present our experience with 5 TS patients whose condition was effectively controlled through treatment of the primary malignant disease. Therefore, we suggest that patients with TS may be cured by tumor resection, even if they have severe thromboembolic disease, such as cerebral or pulmonary infarction.
\end{abstract}

\section{Introduction}

Several cases of unexplained thromboembolic events occurring in patients with malignant tumors have been reported. These events were first described by Trousseau in 1865 (1) and named Trousseau's syndrome (TS). TS is typically associated with mucin-producing tumors, such as pancreatic, gastric or pulmonary carcinoma $(2,3)$.

TS was considered to be infrequently associated with ovarian cancer, representing $3.8 \%$ of all malignant diseases, until 1977 (2). Planner et al then suggested that thromboembolic events may be more common in ovarian cancer patients than previously reported, occurring in $44 \%$ of 59 patients with ovarian cancer and coagulation abnormalities (4).

Recently, an increasing number of patients with ovarian cancer have been reported to experience TS, providing an

Correspondence to: Dr Kentaro Nakayama, Department of Obstetrics and Gynecology, Shimane University School of Medicine, Enyacho 89-1, Izumo, Shimane 6938501, Japan

E-mail:kn88@med.shimane-u.ac.jp

Key words: Trousseau's syndrome, cerebral infarction, thromboembolism, ovarian cancer, endometrial cancer, surgery, unfractionated heparin opportunity to expand our knowledge regarding the treatment of this syndrome. Thromboembolism in the brain is very difficult to treat in several types of TS, and there are currently no specific treatment guidelines.

We herein present a case series of 5 patients with ovarian or endometrial cancer who experienced cerebral infarction due to TS. We investigated biomarkers for early detection of TS and evaluated treatment strategies for these patients. We may predict acute thromboembolism by measuring D-dimer levels, which were found to be increased in this disease, and we observed that the patients' condition could be controlled by treatment of the primary malignant disease. Of the 5 cases presented in this study, 1 case has been previously published as a case report (5).

\section{Patients and methods}

Patients. From October, 2005 to September, 2014, 485 patients suffering from endometrial, ovarian, or cervical cancer were treated at the Shimane University Hospital (Izumo, Japan). Among these patients, 5 patients experienced cerebral infarction associated with TS. The treatment outcomes of patients with TS were analyzed by reviewing their medical backgrounds, medical records and surgical reports (Fig. 1).

Patient background. The frequency of TS among patients with gynecological malignant disease at our hospital is shown in Table I. Overall, 2 of 139 patients $(1.43 \%)$ with endometrial cancer and 3 of 244 patients $(2.08 \%)$ with ovarian cancer experienced TS. No cervical cancer patients at our hospital experienced TS. The patient backgrounds are summarized in Table I. The average age of the patients was 57.4 years (range, 48-72 years). The average body mass index was $22.2 \mathrm{~kg} / \mathrm{m}^{2}$ (range, $18.2-27.8 \mathrm{~kg} / \mathrm{m}^{2}$ ). Tumor histology included endometrial cancer ( $n=2$; both endometrioid) and ovarian cancer $(n=3$; 1 endometrioid, 1 serous and 1 clear cell). There was no history of any condition commonly associated with thrombosis, such as uncontrollable diabetes mellitus or hyperlipidemia.

Findings at diagnosis. The findings at diagnosis are summarized in Table II. All 5 patients (100.0\%) had neurological symptoms, including hemiplegia $(n=3)$, facial palsy $(n=2)$, decreased vision $(n=2)$, dizziness $(n=1)$, muscle weakness $(n=1)$ and dysarthria $(n=1)$. Several cerebral infarction lesions were observed in the right hemicerebrum, right parietal lobe, left frontal lobe, right 


\begin{tabular}{|c|c|c|c|c|c|c|c|c|c|c|c|c|c|c|c|}
\hline \multirow[b]{2}{*}{ Case } & \multirow{2}{*}{$\begin{array}{c}\text { Disease } \\
\text { Histological } \\
\text { stage } \\
\end{array}$} & \multirow{2}{*}{\begin{tabular}{|c|}
$\begin{array}{c}\text { Age } \\
\text { (years) } \\
\text { First visit }\end{array}$ \\
\end{tabular}} & \multirow{2}{*}{\begin{tabular}{|c|}
$\begin{array}{c}\text { Age } \\
\text { (years) }\end{array}$ \\
Cerebral \\
infarction \\
\end{tabular}} & \multirow{2}{*}{$\begin{array}{c}\text { Time of } \\
\text { consideration }\end{array}$} & \multirow[b]{2}{*}{ BMI } & \multirow[b]{2}{*}{$\begin{array}{l}\text { Lesion of } \\
\text { cerebral } \\
\text { infarction }\end{array}$} & \multirow[b]{2}{*}{ Symptoms } & \multirow{2}{*}{\begin{tabular}{|c|} 
Thromboembolic \\
discase except \\
cerebral \\
infarction
\end{tabular}} & \multicolumn{2}{|c|}{ D-dimer $(\mu \mathrm{g} / \mathrm{ml})$} & \multirow{2}{*}{$\begin{array}{l}\text { CA-125 } \\
\text { (U/m) } \\
\text { Time of } \\
\text { cercrbal } \\
\text { infaretion }\end{array}$} & \multirow{2}{*}{$\begin{array}{c}\text { Treatment of } \\
\text { thromboembolism }\end{array}$} & \multirow{2}{*}{$\begin{array}{c}\text { Treatment of } \\
\text { primary disease } \\
\text { after TS } \\
\text { diagnosed }\end{array}$} & \multirow{2}{*}{\begin{tabular}{|c|} 
Survival time \\
after TS \\
diagnosed
\end{tabular}} & \multirow[b]{2}{*}{ Outcome } \\
\hline & & & & & & & & & \begin{tabular}{|c|}
$\begin{array}{c}\text { Before } \\
\text { cerebral } \\
\text { infarction }\end{array}$ \\
\end{tabular} & \begin{tabular}{|l} 
Time of \\
cererbal \\
infarction
\end{tabular} & & & & & \\
\hline \multirow{3}{*}{1} & Stage IA & \multirow{3}{*}{48} & \multirow{3}{*}{48} & \multirow{3}{*}{ Primary } & \multirow{3}{*}{27.8} & \multirow{3}{*}{8} & \multirow{3}{*}{$\begin{array}{l}- \text { Left } \\
\text { hemiplegia } \\
\text {-Decreased } \\
\text { vision in } \\
\text { right eye }\end{array}$} & \multirow{3}{*}{$\begin{array}{l}\text { Vegetation on } \\
\text { mitral valve } \\
\begin{array}{l}\text { Biilateral lower } \\
\text { limb }\end{array} \\
\end{array}$} & \multirow{3}{*}{ - } & \multirow{3}{*}{22.5} & \multirow{3}{*}{420} & $\begin{array}{l}\text { Unfractionated } \\
\text { heparin }\end{array}$ & $\begin{array}{l}\text { TAH BSO } \\
\text { omentectomy }\end{array}$ & \multirow{3}{*}{ - } & \multirow{3}{*}{ NED } \\
\hline & $\begin{array}{c}\text { Ovarian } \\
\text { carcinoma }\end{array}$ & & & & & & & & & & & 1 (surgery) & TC 6 courses & & \\
\hline & $\begin{array}{l}\text { Endometrioid } \\
\text { adenocarcinoma } \\
\end{array}$ & & & & & & & & & & & $\begin{array}{c}\text { Warfarin } \\
\text { Heparin calcium }\end{array}$ & & & \\
\hline \multirow{4}{*}{2} & Stage IVB & \multirow{4}{*}{59} & \multirow{4}{*}{59} & \multirow{4}{*}{ Primary } & \multirow{4}{*}{26.7} & & \multirow{4}{*}{\begin{tabular}{l|} 
Dizziness \\
Decreassed \\
vision in \\
right eye
\end{tabular}} & $\begin{array}{l}\text { Vegetation on } \\
\text { mitral value }\end{array}$ & & & & $\begin{array}{c}\text { Unfractionated } \\
\text { heparin }\end{array}$ & 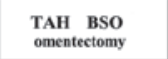 & & \\
\hline & $\begin{array}{c}\text { Endometrial } \\
\text { carcinoma }\end{array}$ & & & & & & & $\begin{array}{l}\text { Renal infarction } \\
\text { Splenic } \\
\text { infarction }\end{array}$ & - & 20.2 & 472 & $\begin{array}{l}\text { Treatment of heart } \\
\text { failure }\end{array}$ & TC 6 courses & 21 months & $\begin{array}{l}\text { Died of } \\
\text { primary }\end{array}$ \\
\hline & $\begin{array}{c}\text { Endometrioid } \\
\text { adenocarcinoma }\end{array}$ & & & & & & & Right lower limb & & & & 1 (surgery) & $\begin{array}{l}\text { Radiation therapy } \\
\text { whole pelvis, } 45 \text { Gly; }\end{array}$ & & \\
\hline & & & & & & & & & & & & $\begin{array}{c}\text { Warfarin } \\
\text { Heparin calcium }\end{array}$ & $\begin{array}{c}\text { PAN } 15 \mathrm{GV} \text { ) } \\
\text { TC4 courses }\end{array}$ & & \\
\hline & Stage IIIC & & & & & & & & & & & $\begin{array}{c}\text { Unfractionated } \\
\text { heparin }\end{array}$ & & & \\
\hline 3 & $\begin{array}{c}\text { Ovarian carcinoma } \\
\text { Clear cell } \\
\text { Carcinoma }\end{array}$ & 53 & 54 & 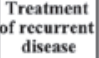 & 20.3 & & $\begin{array}{l}\text { muscle } \\
\text { wealness } \\
\text { Fencial }\end{array}$ & Left lower limb & 0.7 & 23.2 & 552 & \begin{tabular}{|c|} 
Edaravone30 $\mathrm{mgx} 2$ \\
1
\end{tabular} & Chemotherapy & 6 months & $\begin{array}{l}\text { hemorr- } \\
\text { hagic } \\
\text { cerebral }\end{array}$ \\
\hline & G2 & & & & & & & & & & & Warfarin & & & infarction \\
\hline & Stage IIIC & & & & & & Motor & & & & & & & & \\
\hline 4 & \begin{tabular}{|c|} 
Ovarian carcinoma \\
Serous \\
adenocarcinoma \\
G2
\end{tabular} & 55 & 69 & $\begin{array}{c}\text { Palliative } \\
\text { care }\end{array}$ & 18.2 & & $\begin{array}{l}\text { - Dysarthria } \\
- \text {-Right } \\
\text { hemiplegia }\end{array}$ & - & 0.5 & 33.6 & 484 & $\Leftrightarrow$ & Palliative care & 11 days & $\begin{array}{c}\text { multiple } \\
\text { cerebral } \\
\text { infaretions }\end{array}$ \\
\hline 5 & \begin{tabular}{|c|} 
Stage IIB \\
Endometrial \\
carcinoma \\
Endometrioid \\
adenocarcinoma \\
$\mathrm{G} 2$
\end{tabular} & 72 & 72 & Primary & 18.3 & & 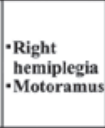 & - & - & 11.7 & 19 & Warfarin & Palliative care & 3 months & $\begin{array}{l}\text { Died of } \\
\text { primary } \\
\text { disease }\end{array}$ \\
\hline
\end{tabular}

Figure 1. Characteristics and treatment outcomes of patients. TS, Trousseau's syndrome; BMI, body mass index; CA-125, carbohydrate antigen-125; TAH, total abdominal hysterectomy; BSO, bilateral salpingo-oophorectomy; PAN, para-aortic nodes; TC, paclitaxel and carboplatin; NED, no evidence of disease.

postcentral gyrus, bilateral posterior lobe, cerebellum and brain stem. Of the 5 patients, $3(60 \%)$ had other types of thromboembolism; among those cases, the thrombosis involved a lower limb in all patients $(3 / 3,100.0 \%)$. Other thrombosis sites included the pulmonary artery $(n=1)$ and the renal and splenic arteries $(n=1)$. Mitral valve vegetations were observed in 2 cases.

Patients with TS exhibited high serum carbohydrate antigen (CA)-125 levels on laboratory examination. The average serum CA-125 level when the infarctions occurred was $390 \mathrm{U} / \mathrm{ml}$ (range, 19-552 U/ml). Moreover, all patients $(5 / 5,100.0 \%)$ presented with significantly elevated D-dimer levels. The average D-dimer level was $41 \mu \mathrm{g} / \mathrm{ml}$ (range, $11.4-108.3 \mu \mathrm{g} / \mathrm{ml}$ ). Of note, these two markers fluctuated in parallel with tumor activity and infarctions occurred when the two markers were elevated simultaneously.

\section{Results}

Thromboembolism treatment results. The treatment results are summarized in Table II. The majority of the patients had received anticoagulation treatment with unfractionated heparin by continuous intravenous drip, and warfarin. This resulted in a good course for 1 patient with recurrent ovarian cancer (case 3), who recovered and was able to resume chemotherapy. However, 3 months later, the patient developed hemorrhagic cerebral infarction, despite an international normalized ratio (INR) of 2.8 (Table II). The patient was unable to receive further active treatment for her recurrent disease and she succumbed 9 days after the second hemorrhagic cerebral infarction (6 months after the first acute cerebral infarction).

The remaining 2 patients (cases 1 and 2) initially received this treatment, but 1 patient (case 2) developed recurrent
Table I. Patients with Trousseau's syndrome.

Primary disease

Cases, $\mathrm{n} / \mathrm{total}(\%)$

Cervical cancer

Endometrial cancer

Ovarian cancer

$3 / 144(2.08)$

Table II. Patient characteristics.

Characteristics

No.

Age at diagnosis, years

$57.4(48-72)$

[median (range)]

Disease

Ovarian cancer 3

Endometrioid cancer

Tumor histology

Endometrial cancer, endometrioid 2

Ovarian cancer, endometrioid 1

Ovarian cancer, clear cell $\quad 1$

Ovarian cancer, serous

$22.2(18.2-27.8)$

Body mass index, $\mathrm{kg} / \mathrm{m}^{2}$

[median (range)]

aseptic vegetations on the mitral valve, whereas cerebral, renal and splenic embolisms recurred during anticoagulation treatment. One patient (case 1) also experienced worsening of a 
Table III. Clinical and laboratory data.

\begin{tabular}{lc}
\hline Data & No. $(\%)$ \\
\hline Symptoms & 3 \\
Hemiplegia & 2 \\
Facial palsy & 1 \\
Dizziness & 2 \\
Decreased vision & 1 \\
Muscle weakness & 1 \\
Dysarthria & \\
Thromboembolic disease & \\
(except cerebral infarction) & $3(60 \%)$ \\
Lower limb & $2(40 \%)$ \\
Vegetations on the mitral valve & 1 \\
Pulmonary artery infarction & 1 \\
Renal and splenic infarction & $390(19-552)$ \\
Laboratory data & \\
CA-125 level at the time of & \\
cerebral infarction, U/ml (range) & \\
D-dimer concentration, $\mu$ g/ml (range) & $(11.4-105.3)$ \\
Under stable conditions & \\
At the time of cerebral infarction &
\end{tabular}

CA-125, carbohydrate antigen- 125 .

Table IV. Treatments and outcomes.

$\begin{array}{lc}\text { Treatment of thromboembolism } & \\ \text { Unfractionated heparin } \rightarrow & 3(60 \%) \\ \text { calcium heparin } \rightarrow \text { warfarin } & \\ \text { Warfarin } & 1 \\ \text { No treatment } & 1\end{array}$

Treatment of primary disease

after diagnosis of TS

Primary treatment for primary disease

Surgery, chemotherapy (PTX+CBDCA)

Surgery, chemotherapy (PTX+CBDCA), RT

Chemotherapy for reccurent disease

Palliative care

Treatment outcomes

NED

Died from primary disease

Died from multiple cerebral infarctions

TS, Trousseau's syndrome; PTX, paclitaxel; CBDCA, carboplatin; RT, radiotherapy; NED, no evidence of disease.

pulmonary embolism (Fig. 2). We therefore decided to treat their primary disease through tumor reduction to provide relief and improve the quality of life. The patients underwent tumor resection, which resulted in disappearance of the thromboembolism. After surgery, anticoagulation therapy was resumed with low-molecular-weight heparin by continuous intravenous drip and subcutaneous injection. The mitral vegetations disappeared and the other emboli almost disappeared.

Another patient with recurrent ovarian cancer (case 4) was unable to receive anticoagulation therapy, as she was already diagnosed with therapy-related myelodysplastic syndrome (WHO; refractory cytopenia with multilineage dysplasia). The patient was at high risk of bleeding due to anticoagulation therapy, so we were only able to monitor her condition and provide best supportive care; her first stroke was widely spread to the brainstem, and she succumbed to acute cerebral infarction 11 days after the stroke.

Primary disease treatment results. One patient (case 1) underwent total hysterectomy + bilateral salpingo-oophorectomy + omentectomy. Optimal debulking surgery without pelvic or para-aortic lymph node dissection was performed, and the patient received adjuvant chemotherapy consisting of carboplatin (area under the curve $=5$ ) and paclitaxel $\left(175 \mathrm{mg} / \mathrm{m}^{2}\right)$. The other patient (case 2) underwent total hysterectomy + bilateral salpingo-oophorectomy + pelvic and para-aortic lymph node dissection, and she received the same chemotherapy as case 1 . In addition, that patient also received radiotherapy (whole pelvic irradiation, $45 \mathrm{~Gy}$; para-aortic lymph nodes, $45 \mathrm{~Gy}$ ). Both patients had a good postoperative course, without recurrence of thromboembolism. One patient (case 2) survived for 21 months after the diagnosis of TS, but eventually succumbed to recurrent malignant disease. The other patient (case 1) remains alive 14 months after treatment, with no evidence of recurrence.

\section{Discussion}

We have treated 5 patients with cerebral infarction due to TS and made two observations regarding this syndrome: First, when the cerebral infarctions occurred, the D-dimer level was suddenly and significantly elevated (Fig. 1; Table III). To the best of our knowledge, this observation was not made by previous studies. As each of these 5 patients experienced sudden elevation of D-dimer levels, we must consider that TS occurs while these levels are elevated. The present results also suggest that, even if patients with progressive malignant disease are treated by anticoagulation therapy, thromboembolism may still occur, despite an INR within the therapeutic range. We may predict the risk of acute thromboembolism by measuring the D-dimer level, which is almost always elevated in this disease. Moreover, we observed an association between D-dimer level and serum CA-125 level. A significant increase in CA-125 levels has been reported in mucin-producing tumors, and TS is known to occur in association with such tumors $(2,6)$. We observed that tumors with mucin-producing characteristics exhibited an association between the levels of D-dimer and serum CA-125 (parallel change) in TS. This suggests a role for potential biomarkers for early development of TS.

Second, we may control thromboembolism by effectively controlling the primary disease. Two patients with recurrence (cases 3 and 4) and 1 patient in whom the primary disease could not be controlled (case 5) succumbed to cerebrovascular disease. By contrast, in the remaining 2 patients 

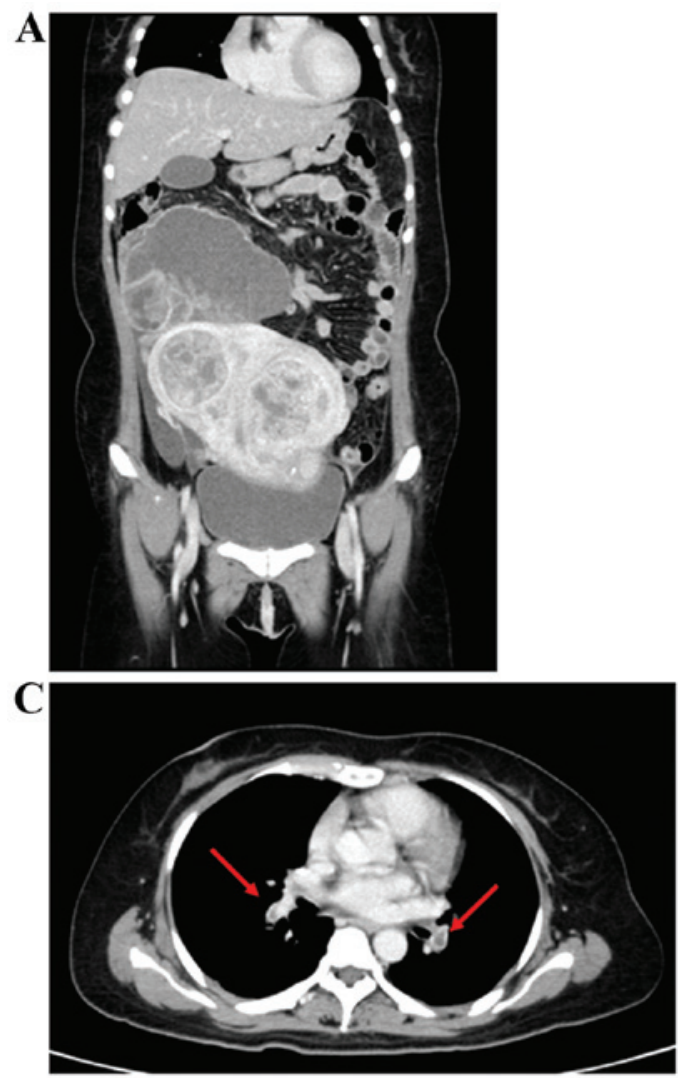

B

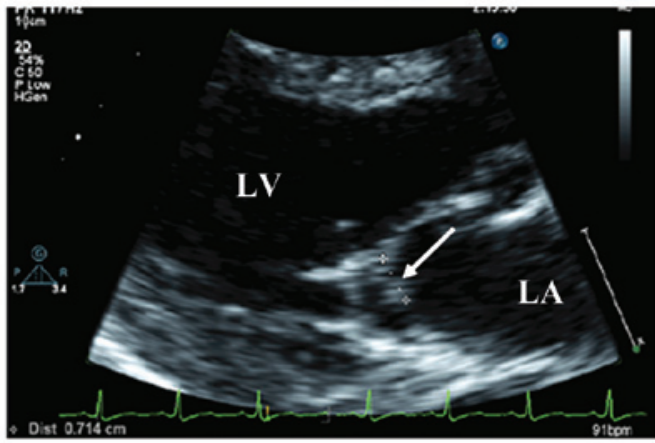

D

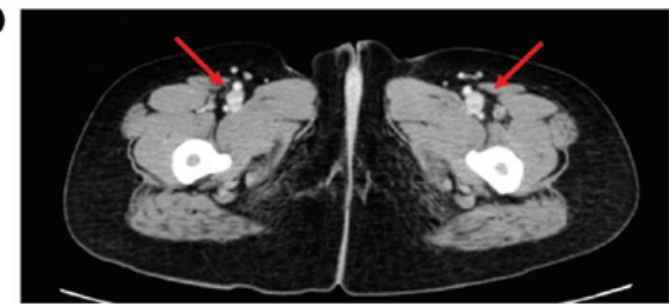

E

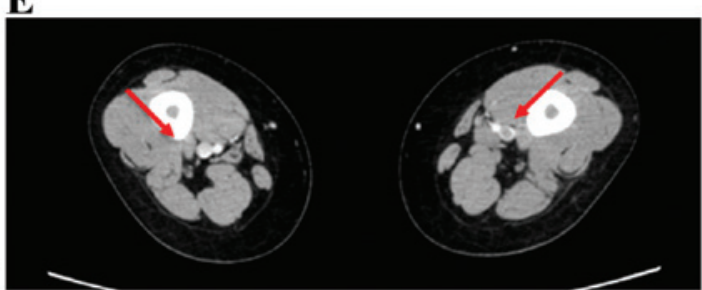

Figure 2. (A) Contrast-enhanced computed tomography (CT) scan revealed a 20-cm multiple uterine myoma and a 10-cm right adnexal tumor that was suspected to be an ovarian malignancy. (B) Transthoracic echocardiography showed vegetations on the mitral valve (arrow). The largest area of vegetation, 7 mm in length, was attached to the anterior leaflet. LA, left atrium; LV, left ventricle. (C-E) CT scan showed (C) emboli in multiple pulmonary arteries (arrows) and (D and E) thrombus formation in the lower limbs bilaterally (arrows).

(cases 1 and 2), who were diagnosed with primary disease and cerebrovascular disease simultaneously, thromboembolism was cured with anticoagulation therapy and tumor resection. The primary approach for treating malignancy-related TS is the elimination of the causative tumor, regardless of the underlying disease mechanism. Treatment directed against the underlying malignancy may also significantly improve the hypercoagulable state.

Levitan et al suggested that the rate of deep venous thrombosis/pulmonary embolism was $16 / 10,000$ for patients with head and neck cancers and 22/10,000 for those with bladder or breast cancer, but it steadily increased to 85, 96, 110, 117 and $120 / 10,000$ for patients with stomach cancer, lymphoma, and tumors of the pancreas, brain and ovaries, respectively (7). Planner et al also suggested that thromboembolic events may be more common in ovarian carcinoma than previously considered, occurring in $44 \%$ of 59 patients with ovarian carcinoma and coagulation abnormalities (4). The definition of TS includes neurological symptoms which occur at distant sites from the malignant tumor and is associated with malignant disease. In a narrow sense, TS was considered to induce strokes due to hypercoagulability, and to have a poor prognosis (8). It has been reported that patients with lung, prostate, breast or ovarian carcinoma, or malignant hematological diseases, tend to suffer from cerebral infarction more frequently compared with patients with other malignant diseases (9).

The primary approach to treating TS is to eliminate the causative tumor; however, this is often not possible. It is commonly mentioned in the literature that heparin is the preferred treatment (2,10-15). In recent years, low-molecular-weight heparins have become popular, in part due to their improved pharmacokinetics, the ability to administer single daily dosages, and the reduced incidence of heparin-induced thrombocytopenia (16-18). In 2 of our patients, we initially used low-molecular-weight heparins, but eventually switched to warfarin, as it was difficult for the patients to continue using heparin at home, although it is well known that heparins are better for the treatent of TS.

In this report, we described cerebral infarction with TS due to malignant gynecological disease. Thromboembolisms in the brain may be difficult to treat in several types of TS. We experienced cases in which both TS and the primary disease could be effectively controlled with conventional heparin treatment.

We treated 5 TS patients whose condition could be controlled through treatment of the primary malignant disease (Table IV). Patients with TS with recurrent and difficult-to-control malignant disease are almost impossible to cure. It is well known that if the primary disease is difficult to control, the patients have a poor prognosis.

To the best of our knowledge, this is the first report to describe the association between D-dimer and serum CA-125 level as potential biomarkers for TS. In addition, if patients have cerebral infarction and pulmonary embolism, cancer treatment need not be discontinued, as it is possible to treat patients with TS via tumor resection. 


\section{References}

1. Trousseau A: Phlegmasia alba dolens. Lectures on Clinical Medicine, delivered at the Hotel-Dieu, Paris. Vol. 5. London, England: New Sydenham Society, pp281-332, 1865.

2. Sack GH Jr, Levin J and Bell WR: Trousseau's syndrome and other manifestations of chronic disseminated coagulopathy in patients with neoplasms: Clinical, pathophysiologic, and therapeutic features. Medicine (Baltiinore) 56: 1-37, 1977.

3. Viselli AL, Feuer GA and Granai CO: Lower limb ischemic venous thrombosis in patients with advanced ovarian carcinoma. Gynecol Oncol 49: 262-265, 1993.

4. Planner RS, O'Sullivan EF, Campbell JJ and Ball DL: The hypercoagulable state and pulmonary embolism in patients with ovarian carcinoma. Aust N Z J Obstet Gynaecol 18: 209-212, 1978.

5. Ito S, Yoshitomi H, Pak M, Kawahara H, Oshima T, Ito S, Watanabe N, Sato H, Adachi T, Takeda M, et al: Trousseau syndrome with nonbacterial thrombotic endocarditis in a patient with uterine cancer. Intern Med 52: 1353-1358, 2013.

6. Shao B, Wahrenbrock MG, Yao L, David T, Coughlin SR, Xia L, Varki A and McEver RP: Carcinoma mucins trigger reciprocal activation of platelets and neutrophils in a murine model of Trousseau syndrome. Blood 118: 4015-4023, 2011

7. Levitan N, Dowlati A, Remick SC, Tahsildar HI, Sivinski LD, Beyth R and Rimm AA: Rates of initial and recurrent thromboembolic disease among patients with malignancy versus those without malignancy. Risk analysis using Medicare claims date Medicine (Baltimore) 78: 285-291, 1999.

8. Vernon S: Trousseau's syndrome: Thrombophlebitis with carcinoma. J Abdom Surg 3: 137-138, 1961.

9. Cestari DM, Weine DM, Panageas KS, Segal AZ and DeAngelis LM: Stroke in patients with cancer: Incidents and etiology. Neurology 62: 2025-2030, 2004.

10. Zhang YY, Chan DK, Cordato D, Shen Q and Sheng AZ: Stroke risk factor, pattern and outcome in patients with cancer. Acta Neurol Scand 114: 378-383, 2006
11. Bell WR, Starksen NF, Tong S and Porterfield JK: Trousseau's syndrome. Devastating coagulopathy in the absence of heparin. Am J Med 79: 423-430, 1985

12. Krauth D, Holden A, Knapic N, Liepman M and Ansell J: Safety and efficacy of long-term oral anticoagulation in cancer patients. Cancer 59: 983-985, 1987.

13. Walsh-McMonagle D and Green D: Low-molecular-weight heparin in the management of Trousseau's syndrome. Cancer 80: 649-655, 1997.

14. Meyer G, Marjanovic Z, Valcke J, Lorcerie B, Gruel Y, Solal-Celigny P, Le Maignan C, Extra JM, Cottu P and Farge D: Comparison of low-molecular-weight heparin and warfarin for the secondary prevention of venous thromboembolism in patients with cancer: A randomized controlled study. Arch Intern Med 162: 1729-1735, 2002

15. Levine MN: Managing thromboembolic disease in the cancer patient: Efficacy and safety of antithrombotic treatment options in patients with cancer. Cancer Treat Rev 28: 145-149, 2002.

16. Castelli R, Porro F and Tarsia P: The heparins and cancer: Review of clinical trials and biological properties. Vasc Med 9: 205-213, 2004.

17. Zacharski LR and Loynes JT: Low-molecular-weight heparin in oncology. Anticancer Res 23: 2789-2793, 2003.

18. McCart GM and Kayser SR: Therapeutic equivalency of low-molecular-weight heparins. Ann Pharmacother 36: 1042-1057, 2002. 